\title{
Downregulation of $\mathrm{LH}$ receptor mRNA in the rat uterus
}

\author{
YOSHIMITSU KASAHARA, YOSHIKAZU KITAHARA, KAZUTO NAKAMURA and TAKASHI MINEGISHI
}

\author{
Department of Obstetrics and Gynecology, Gunma University \\ Graduate School of Medicine, Maebashi, Gunma 371-8511, Japan
}

Received November 17, 2011; Accepted February 13, 2012

DOI: $10.3892 / \mathrm{mmr} .2012 .795$

\begin{abstract}
We detected luteinizing hormone receptor (LHR) mRNA in the immature rat uterus by northern blotting and downregulation of this receptor mRNA after pregnant mare serum gonadotropin (PMSG)-human chorionic gonadotropin (hCG) treatment. After administration of hCG, the mRNA levels in the rat uterus declined to an extremely low level from Days 1 to 3 and then rebounded and reached higher than pretreatment values at Day 4. At Day 5 the levels were 3-fold higher than the control levels. The cultured uterus displayed an hCG concentration-dependent increase in cAMP production in the medium. Immunohistochemical experiments showed that these receptor proteins were expressed in the epithelial cells of the endometrium. These results suggest that functional LHRs are present in the immature rat uterus and are downregulated by signals resulting from hCG treatment. These data may support the idea that LH acts on the uterus to inhibit contraction at ovulation. Although the precise role of the LHR in the uterus remains unknown, this study may provide a model with which to investigate the regulation of LHR.
\end{abstract}

\section{Introduction}

The interaction of luteinizing hormone $(\mathrm{LH})$, or its human placental counterpart, human chorionic gonadotropin (hCG), with its receptor, is a key event in the regulation of steroidogenesis in the mammalian ovary. The expression of this receptor was previously thought to be restricted to gonadal tissue. However, recent studies have shown its presence in many other tissues throughout the reproductive and non-reproductive organs. High-affinity LH/hCG binding sites have been detected, among other sites, in the pig (1), rabbit (2), rat (3) and female (4) uterus. Until recently the physiological significance of the uterine luteinizing hormone receptor (LHR) has remained poorly understood, since its study is difficult due to the low binding capacity of the tissue.

Correspondence to: Dr Takashi Minegishi, Department of Obstetrics and Gynecology, Gunma University Graduate School of Medicine, 3-39-22 Showa-machi, Maebashi, Gunma 371-8511, Japan

E-mail: tminegis@gunma-u.ac.jp

Key words: luteinizing hormone receptor, uterus, luteinizing hormone, human chorionic gonadotropin, downregulation
Several studies have indicated that hCG signals also act on the endometrium (5) and modulate stromal and epithelial cell activities. In addition, it has been reported that LHR mRNA and protein are also expressed in the human endometrium, with maximal expression in epithelial cells during the secretory phase $(6,7)$.

LHRs expressed on rat ovarian granulosa cells of preovulatory follicles and luteal cells are greatly diminished after an endogenous pre-ovulatory LH surge or by the administration of a pharmacological dose of hCG (8). Previous studies have shown that mevalonate kinase (Mvk) exists in the rat ovary and plays a role in the downregulation of LHR induced by the administration of a pharmacological dose of hCG. As Mvk is an LHR mRNA-binding protein, Mvk binding to LHR mRNA accelerated the LHR mRNA instability (9). We also previously showed that upregulation of LHR mRNA is inversely correlated to Mvk mRNA levels in rat granulosa cell culture (10). Studies of LH-hypersecreting transgenic mice have demonstrated that females are infertile; this infertility manifests at the level of uterine receptivity and pregnancy maintenance (11). Thus, we examined the effect of hCG on the expression of the LHR in the immature rat uterus.

\section{Materials and methods}

Hormones and reagents. Purified hCG was supplied by Dr A. Parlow and the National Hormone and Peptide Program (National Institute of Diabetes and Digestive and Kidney Disease, National Institutes of Health) (Torrance, CA). DMEM/Ham's nutrient mixture F-12 and diethylstilbestrol (DES) were purchased from Sigma Chemical Co. (St. Louis, MO). Gentamicin sulfate and fungizone were purchased from Invitrogen Corp. (Carlsbad, CA). The hCG for the in vivo study was provided by Schering-Plough Corp. (Osaka, Japan), and pregnant mare serum gonadotropin (PMSG) was provided by Asuka Pharmaceutical (Tokyo, Japan). The RNA labeling and nucleic acid detection kits were purchased from Boehringer Mannheim (Mannheim, Germany).

Animal treatment. Female 21-day-old Wistar rats (Japan SLC, Inc., Hamamatsu, Japan) were maintained according to National Institutes of Health guidelines for the Care and Use of Laboratory Animals and the policies of the Gunma University Animal Care and Use Committee. Animals were housed in a temperature- and light-controlled room (12-h light, 12-h dark cycle; lights on at 6:00 am) with food and water 
provided ad libitum. For the in vivo study, 21-day-old female rats received an s.c. injection of PMSG (Serotropin, Asuka Pharmaceutical Co.) (30 IU), and then an s.c. injection of hCG (20 IU) after $48 \mathrm{~h}$. In addition, as in another in vivo experiment, 21-day-old female rats received an s.c. injection of hCG (20 IU). To extract uterine mRNA, the rats were sacrificed for removal of the uterus on Days 0, 1, 2, 3, 4 and 5 after the injection of hCG. For investigation of diethylstilbestrol (DES) treatment, rats received s.c. injections $(2 \mathrm{mg})$ of DES for 4 days, and rat uteri were removed. The uteri were immediately stored in RNAlater Tissue Collection (Applied Biosystems, Foster City, CA) until northern blot analysis and RT-PCR analysis.

Immunohistochemical analysis of LHR in PMSG-hCG-treated immature rat uterus. Immature rat uteri and ovaries after 4 days of PMSG-hCG treatment were immersion-fixed in formalin solution for $24-48 \mathrm{~h}$ at room temperature, dehydrated in graded ethanol, cleared in xylene, and embedded in paraffin. Immunostaining was performed in uterine sections $(5 \mu \mathrm{m})$ using the Histofine SAB-PO (goat) kit (Nichirei Bioscience, Inc.). Tissue sections were stained with a rabbit polyclonal antibody, anti-LHR (sc -25828; Santa Cruz Biotechnology, Inc., Santa Cruz, CA) at a 1:50 dilution. Negative controls were performed in which the primary antibody was substituted with the normal rabbit IgG (sc -2027; Santa Cruz Biotechnology, Inc.) at a 1:100 dilution. The immunoreactive product was visualized using diaminobenzidine and sections were lightly counterstained with hematoxylin.

RNA isolation and northern blot analysis. RNA was extracted using Isogen (Nippon Gene, Toyama, Japan) according to the manufacturer's protocol. The final RNA pellet was dissolved in diethyl pyrocarbonate-treated $\mathrm{H}_{2} \mathrm{O}$. Total-RNA was quantified by measuring the absorbancy of samples at $260 \mathrm{~nm}$. For northern blot analysis, $15 \mu \mathrm{g}$ total-RNA was separated by electrophoresis on denaturing agarose gels and subsequently transferred to a nylon membrane (Biodyne, Inc., Glen Cove, NY, USA). Rat LHR cDNA was prepared as described previously and linearized with BglII (12). Digoxigenin-labeled LHR cRNA probes corresponding to bases 440-2560 were produced by in vitro transcription with $\mathrm{T}_{3}$ RNA polymerase and an RNA labeling kit (Roche Diagnostics). In accordance with the standard protocol for the nucleic acid detection kit (Boehringer Mannheim), Kodak X-Omat film (Eastman Kodak, Rochester, NY) was then exposed to the membranes. Luminescence detection was quantified with an LKB 2202 UnitroScan Laser Densitometer (LKB Produkter AB, Bromma, Sweden), normalized against a corresponding relative amount of GAPDH mRNA in each sample, and expressed as relative densitometric units.

Reverse transcription and quantitative PCR. Total-RNA was isolated from the rat uterus, and the concentrations were measured, as described above. The isolated RNAs $(2 \mu \mathrm{g}$ of each sample) were treated with DNAse I (Invitrogen) to eliminate residual genomic DNA. These RNAs were reversetranscribed with random primers, $10 \mathrm{mM}$ deoxynucleoside triphosphate mix, and SuperScript III reverse transcriptase (Invitrogen) according to the manufacturer's protocol. The reactions were incubated for $5 \mathrm{~min}$ at $25^{\circ} \mathrm{C}, 60 \mathrm{~min}$ at $50^{\circ} \mathrm{C}$,
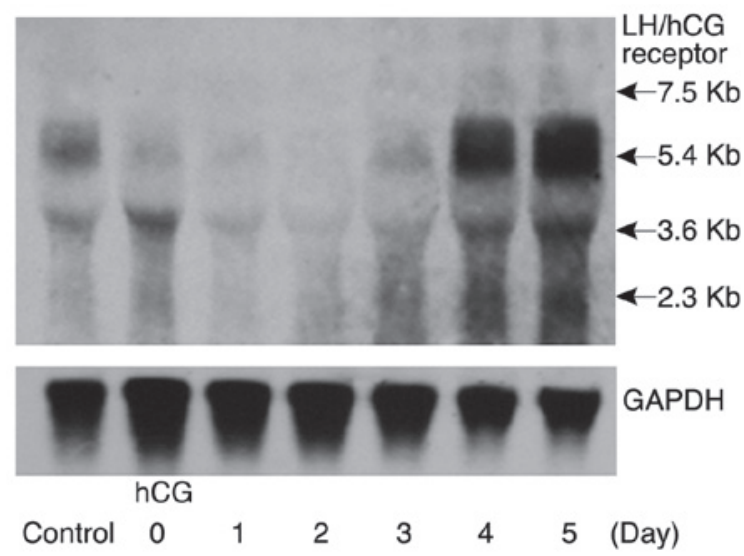

Figure 1. Northern blot analysis results of LHR in PMSG-hCG-treated immature rat uterus. Rats (21-day-old females) received an s.c. injection of PMSG (30 IU), and then an s.c. injection of hCG (20 IU) after $48 \mathrm{~h}$. RNA was extracted using Isogen according to the manufacturer's protocol. For the northern blot analysis, $15 \mu \mathrm{g}$ total-RNA from uterus was separated by electrophoresis on denaturing agarose gels and was subsequently transferred to a nylon membrane. Data shown are representative of three independent experiments.

and $15 \mathrm{~min}$ at $70^{\circ} \mathrm{C}$ in a thermal cycler. To remove complementary RNA, RNase $\mathrm{H}$ was added to the cDNAs and incubated for $20 \mathrm{~min}$ at $37^{\circ} \mathrm{C}$. The real-time RT-PCR was performed using TaqMan Gene Expression assays (luteinizing hormone/ choriogonadotropin receptor: Rn00564309_m1, Eukaryotic 18S rRNA: Hs99999901_s1 as an internal control; Applied Biosystems) according to the instructions of the manufacturer. Relative quantification of mRNA species were carried out using the comparative threshold (CT) cycles method. For each sample, we normalized the gene CT value using the formula: $\Delta \mathrm{CT}=\mathrm{CT}$ gene - CT 18S. For relative expression levels, the following formula was used: $\Delta \Delta \mathrm{CT}=\Delta \mathrm{CT}$ sample $-\Delta \mathrm{CT}$ calibrator. This value was then used to plot the gene expression employing the formula $2^{-\Delta \Delta \mathrm{CT}}$. Mvk (Rn00579228-m1), PR (Rn01405937-ml) and p120 (Rn01405937-ml) expression levels were measured in the same way as in the LHR mRNA assay.

Culture of rat uterine tissues. Rat uterine tissues were cut into 3 -mm cubes, and five of them were placed into each well of a 24-well culture plate with medium. After a 30-min preincubation, the medium was exchanged with medium containing $0.5 \mathrm{mM}$ 3-isobutyl-1-methylxanthine (IBMX) (Sigma Chemical Co.). The incubation was continued for $2 \mathrm{~h}$ at $37^{\circ} \mathrm{C}$ in the presence and absence of purified hormone. At 1 and $2 \mathrm{~h}$, the medium was removed and cAMP levels were determined by the double-antibody radioimmunoassay method (13). Triplicate plates were analyzed for each data point.

Data analysis. The data are presented as means \pm SE of measurements from triplicate samples for one representative experiment. Comparisons between groups were performed by one-way ANOVA. The significance of differences between the mean values in the control group and each treated group was determined by Duncan's multiple comparison test. A $\mathrm{P}$-value $<0.05$ was considered to denote statistical significance. 

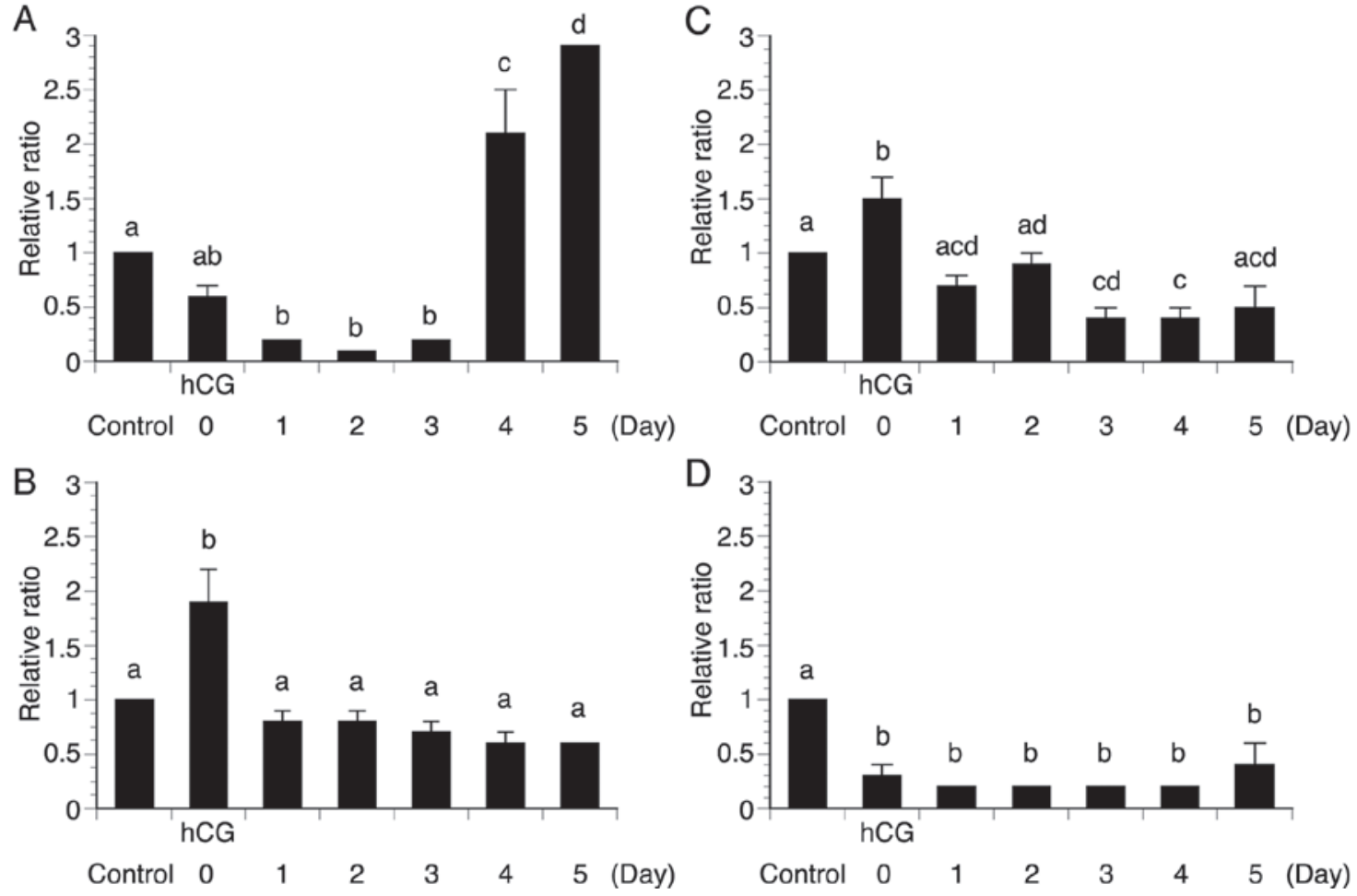

Figure 2. RT-PCR results of (A) LHR, (B) Mvk, (C) PR and (D) p120 in PMSG-hCG-treated immature rat uterus. Rats (21-day-old females) received an s.c. injection of PMSG (30 IU), and then an s.c. injection of hCG (20 IU) after 48 h. RNA was extracted using Isogen. ABI TaqMan Gene Expression assays were used as described in Materials and methods. Relative quantification of mRNA species was carried out using the comparative threshold (CT) cycles method using the same uterus as described in Materials and methods. Data were normalized for GAPDH mRNA levels in each sample and expressed relative to the control value (mean $\pm \mathrm{SE} ; \mathrm{n}=3$ ). The values indicated by different alphabetical letters are significantly different $(\mathrm{P}<0.05)$.

\section{Results}

Northern blot analysis and RT-PCR results of LHR $m R N A$ in the rat uterus. The concentration-dependent and developmental stage-specific actions of gonadotropins indicate the complexity of the regulatory mechanisms operating in gonadal target cells. To see the effect of hCG under a physiological condition, we pretreated the uterus of female rats with PMSG and $48 \mathrm{~h}$ later hCG was injected. In a previous experiment on the rat ovary, exposure to a gonadotropin caused a decrease in LHR mRNA after $12 \mathrm{~h}$; by Day 2, the mRNA levels had returned to control levels, and by Day 3, the levels were higher than those of the controls. In the present experiment, northern blot analysis of rat uterine mRNA indicated one major 5.4-kilobase (kb) and several minor transcripts; a similar pattern of mRNA transcripts was observed in the rat ovary. Northern blot analysis and RT-PCR results showed that mRNA levels in the uterus decreased by Day 1 and maintained this low level; then by Day 4, these levels rebounded and were higher than those of the controls. At Day 5, the level was 3-fold higher than the control level (Figs. 1 and 2A).

RT-PCR results of $L H R, M v k, P R$ and $p 120$. Since LHR expression in the ovary is regulated post-transcriptionally by Mvk, which acts as an RNA-binding protein, we measured the expression of Mvk with same time course of LHR in the uterus. As shown in Fig. 2A and B, the results of LHR mRNA confirmed the findings indicated in Fig. 1 and Mvk mRNA increased after PMSG treatment and gradually decreased after hCG treatment.
Since previous studies have shown that the progesterone receptor (PR) is rapidly induced in the follicles following $\mathrm{LH}$ surge, we examined the expression levels of PR and p120, which is a transcriptional co-activator of androgen and PR. The level of PR mRNA increased after administration of PMSG and decreased after hCG treatment, and the level of p120 mRNA was suppressed by the same treatment in the uterus (Fig. 2C and D).

In the following experiments, the effect of single treatment with hCG was examined, and the time course of change of the mRNA level of the LHR was similar to the pattern for PMSG pretreatment. Treatment with hCG caused a downregulation and subsequent upregulation to previous levels of receptor mRNA (data not shown).

Since estradiol has a significant effect on the expression of LHR in the ovary, we examined the effect of DES in immature rats. However, we could not detect any significant effect of DES on the expression of LHR in the rat uterus (data not shown).

Effect of hCG on cAMP production in the uterus. To confirm that the expressed LHR is functional, cAMP accumulation in the medium after hCG treatment was examined. The uterus displayed a significant increase in $\mathrm{cAMP}$ production in the medium after 1 and $2 \mathrm{~h} ; 50$ and $100 \mathrm{ng} / \mathrm{ml}$ hCG significantly increased cAMP levels in the medium compared with that of the control (Fig. 3).

Immunohistochemical analysis of $L H / h C G$ protein in the uterus. Immunohistochemical analysis of immature rat ovaries after 4 days of PMSG-hCG treatment showed strong staining 


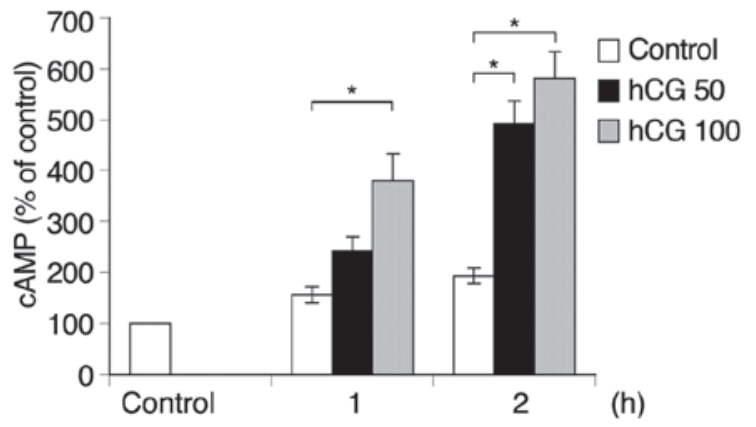

Figure 3. Time course of effect of hCG on extracellular cAMP accumulation of the rat uterus. Rat uterine tissues were cut into 3-mm cubes, and 5 of them were placed into each well of a 24 -well culture plate with medium. After a 30-min preincubation, the medium was exchanged with medium containing $0.5 \mathrm{mM} 3$-isobutyl-1-methylxanthine (IBMX). The incubation was continued for $2 \mathrm{~h}$ at $37^{\circ} \mathrm{C}$ in the presence and absence of purified hormone. The medium was stocked at the indicated time and extracellular cAMP levels were determined by double-antibody radioimmunoassay. Each data point represents the mean \pm SE for triplicate plates. Control value is $14 \pm 1.2 \mathrm{pmol} / \mathrm{ml}$. *Difference from the control value at $\mathrm{P}<0.05$.

for LHR in the corpus luteum as expected (Fig. 4A and B). Although it has been controversial whether the LHR protein is expressed in the endometrium or myometrium of the uterus, this immunohistological experiment showed that it resides in the epithelium of endometrium in the uterus (Fig. 4C and D).

\section{Discussion}

It has been reported that the rat uterus contains LHR with an affinity constant for hCG that is analogous to that of rat ovarian receptors as shown in a previous study (3). The binding characteristics of these receptors were found to be similar to those reported for other animals $(1,2)$, and these receptors have a high-binding-affinity constant and low-binding capacity. A number of studies have reported that LHRs are expressed in a variety of extragonadal tissue, however often only LHR mRNA has been identified using RT-PCR without northern blot analysis and most of the data have been obtained in vitro. We detected LHR mRNA in uterus by northern blot analysis with a similar pattern of ovarian LHR mRNA and confirmed this expression by RT-PCR.

In previous experiments, hCG induced the downregulation of LHR mRNA levels in the rat ovary; this process was followed by the downregulation of membrane receptor levels $(8,14,15)$. In a previous investigation of the rat ovary (8), exposure to a gonadotropin caused a decrease in LHR mRNA after $12 \mathrm{~h}$, and this effect was transient; by Day 2, the mRNA levels had returned to control levels, and by Day 3, the levels were higher than those of the controls. In the present experiment, mRNA levels in the uterus decreased by Day 1; by Day 4, these levels had rebounded to be higher than those of the controls. These results showed that hCG addition transiently decreased LHR mRNA levels in the ovary and uterus, followed by an increase in LHR mRNA levels. The mechanism of LHR mRNA regulation in the rat uterus remains unknown, but the duration of the decrease in mRNA was prolonged compared with that in the ovary. These observations suggest that a labile destabilizing factor, induced by gonadotropin, may degrade LHR mRNA.

Mvk, a cytosolic enzyme in the cholesterol biosynthetic pathway, was cloned from the rat liver in 1990 (16). Because the ovary is one of the major steroidogenic endocrine tissues, it
A

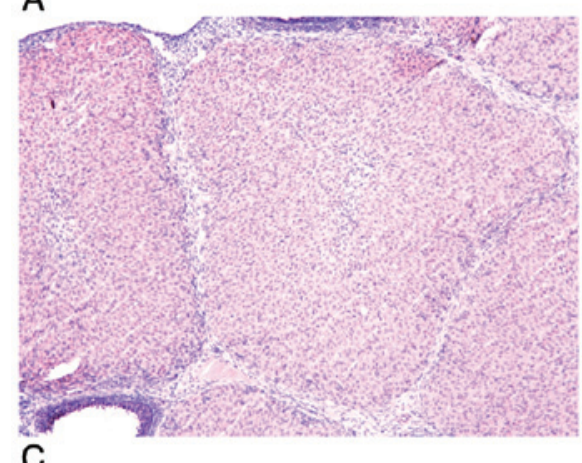

C

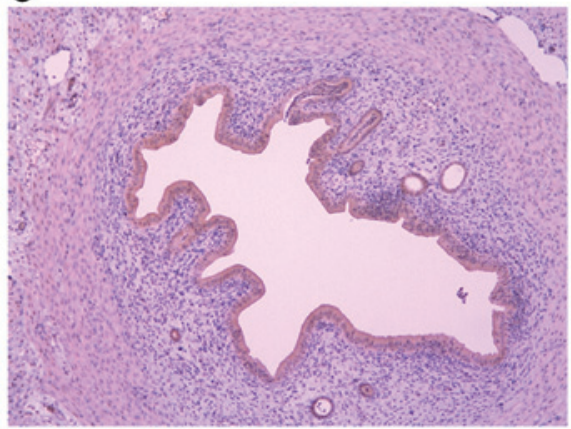

B

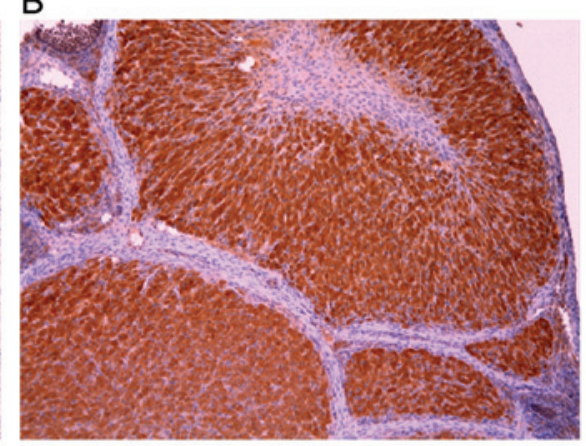

D

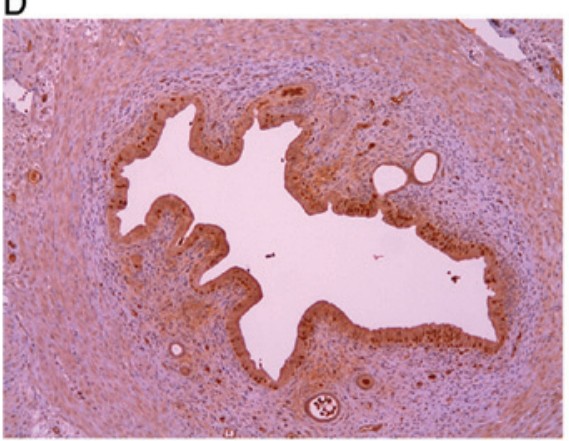

Figure 4. Immunohistochemical analysis of LHR in PMSG-hCG-treated immature rat ovary and uterus. Immature rat uteri and ovaries after 4 days of PMSG-hCG treatment were immersion-fixed in formalin solution, dehydrated in graded ethanol, cleared in xylene, and embedded in paraffin. Tissue sections were stained with a rabbit polyclonal antibody, and anti-LHR at a 1:50 dilution. (A) The ovary and (C) the uterus; negative controls, non-immune IgG applied to section at equivalent concentration as the primary antibody. Representative photomicrographs of rat LHRs localized to (B) the corpus luteum and (D) the epithelium of endometrium in the uterus. 
is no wonder that Mvk exists and is involved in sterol synthesis in the ovary. In fact, Mvk enzyme activity has already been demonstrated in the ovary (17). Moreover, studies from the laboratory of Wang et al (9) revealed that Mvk is an LHR mRNA-binding protein and that Mvk binding to LHR mRNA accelerates LHR mRNA instability. We previously found that estradiol reduced the Mvk levels in granulosa cells, by which LHR mRNA was consequently increased. It has been reported that estradiol benzoate increased the concentration of myometrial LHR in vivo (18). However, in this experiment we could not detect the effect of DES on the expression of LHR in the uterus; therefore, estradiol may not be a major factor in the receptor expression in the uterus. In addition, we could not detect a significant increase in the expression of either PR or P120 after hCG injection, which are both induced in the ovary by the treatment of gonadotropin (19). Therefore, this downregulation in LHR in the uterus may not be related with steroid synthesis in the ovary. Furthermore, the single injection of hCG in immature rats also reduced the expression of LHR mRNA in the uterus (data not shown), suggesting that the signals induced by hCG except for steroid products may cause the downregulation of mRNA of this receptor in the uterus.

PMSG, which includes FSH and LH activity in the rat, induced Mvk expression by $48 \mathrm{~h}$ before hCG treatment in this experiment, and this rise in mRNA of Mvk may relate to the downregulation of LHR in the uterus. As the LHR mRNA downregulation may be induced by several biological pathways including microRNAs, we speculate that prolonged LHR downregulation in the uterus may be related to the upregulation of the Mvk protein and some microRNAs (unpublished data).

Interaction of $\mathrm{LH} / \mathrm{hCG}$ with its receptor is a key event in the regulation of steroidogenesis in the mammalian ovary. In the present study, hCG treatment caused a dose-responsive increase in cAMP release from the uterus into the incubation medium. These data showed that the LHR expressed in the uterus has a function, although the biological effect on the uterus is not clear and the physiological role of LH/hCG binding sites in the uterus remains to be elucidated. Ziecik et al (1) and Angioni et al (20) postulated the role of $\mathrm{LH}$ in the relaxation of the myometrium; these findings are in agreement with results that preferentially locate $\mathrm{LH} / \mathrm{hCG}$ binding sites in this uterine compartment. It has been reported that transgenic mice with chronically elevated $\mathrm{LH}$ are infertile due to anovulation and defects in uterine receptivity (11). We speculate that chronic LH hypersecretion may cause LHR downregulation in the uterus and the lack of LH effect may compromise fertility at the level of uterine receptivity.

In this study, we found that the LHR resides in the epithelium of the endometrium; this immunohistochemical finding does not necessarily conflict with the notions that LH may stimulate the production of cAMP in the epithelium, that they are distributed in a local area including the myometrium and that they prevent uterine contraction. Although the role of the LHR in the uterus during pregnancy remains unknown in the rodent, where CG is absent, this study may provide a model with which to investigate the regulation of LHR in the uterus.

\section{Acknowledgements}

This study was supported by a grant from the Ministry of Education, Science and Culture of Japan (21390448, 22659295).
We thank Hiroko Matsuda and Junko Sakurai for their excellent technical assistance. We also thank Rika Kuroda for her excellent secretarial assistance.

\section{References}

1. Ziecik AJ, Stanchev PD and Tilton JE: Evidence for the presence of luteinizing hormone/human chorionic gonadotropin-binding sites in the porcine uterus. Endocrinology 119: 1159-1163, 1986.

2. Jensen JD and Odell WD: Identification of LH/hCG receptors in rabbit uterus. Proc Soc Exp Biol Med 189: 28-30, 1988.

3. Bonnamy PJ, Benhaim A and Leymarie P: Estrous cycle-related changes of high affinity luteinizing hormone/human chorionic gonadotropin binding sites in the rat uterus. Endocrinology 126: 1264-1269, 1990.

4. Reshef E, Lei ZM, Rao CV, Pridham DD, Chegini N and Luborsky JL: The presence of gonadotropin receptors in nonpregnant human uterus, human placenta, fetal membranes, and decidua. J Clin Endocrinol Metab 70: 421-430, 1990.

5. Strakova Z, Mavrogianis P, Meng X, et al: In vivo infusion of interleukin-1beta and chorionic gonadotropin induces endometrial changes that mimic early pregnancy events in the baboon. Endocrinology 146: 4097-4104, 2005.

6. Perrier d'Hauterive S, Berndt S, Tsampalas M, et al: Dialogue between blastocyst hCG and endometrial LH/hCG receptor: which role in implantation? Gynecol Obstet Invest 64: 156-160, 2007.

7. Perrier d'Hauterive S, Charlet-Renard C, Berndt S, et al: Human chorionic gonadotropin and growth factors at the embryonicendometrial interface control leukemia inhibitory factor (LIF) and interleukin 6 (IL-6) secretion by human endometrial epithelium. Hum Reprod 19: 2633-2643, 2004.

8. Nakamura K, Minegishi T, Takakura Y, et al: Hormonal regulation of gonadotropin receptor mRNA in rat ovary during follicular growth and luteinization. Mol Cell Endocrinol 82: 259-263, 1991.

9. Wang L, Gulappa T and Menon KM: Identification and characterization of proteins that selectively interact with the LHR mRNA binding protein (LRBP) in rat ovaries. Biochim Biophys Acta 1803: 591-597, 2010.

10. Ikeda S, Nakamura K, Kogure K, et al: Effect of estrogen on the expression of luteinizing hormone-human chorionic gonadotropin receptor messenger ribonucleic acid in cultured rat granulosa cells. Endocrinology 149: 1524-1533, 2008.

11. Mann RJ, Keri RA and Nilson JH: Transgenic mice with chronically elevated luteinizing hormone are infertile due to anovulation, defects in uterine receptivity, and midgestation pregnancy failure. Endocrinology 140: 2592-2601, 1999.

12. Nakamura K, Nakamura M, Igarashi S, et al: Effect of activin on luteinizing hormone-human chorionic gonadotropin receptor messenger ribonucleic acid in granulosa cells. Endocrinology 134: 2329-2335, 1994.

13. Hattori M, Ozawa K and Wakabayashi K: Sialic acid moiety is responsible for the charge heterogeneity and the biological potency of rat lutropin. Biochem Biophys Res Commun 127: 501-508, 1985

14. Hu ZZ, Tsai-Morris CH, Buczko E and Dufau ML: Hormonal regulation of $\mathrm{LH}$ receptor $\mathrm{mRNA}$ and expression in the rat ovary. FEBS Lett 274: 181-184, 1990.

15. LaPolt PS, Oikawa M, Jia XC, Dargan C and Hsueh AJ: Gonadotropin-induced up and downregulation of rat ovarian LH receptor message levels during follicular growth, ovulation and luteinization. Endocrinology 126: 3277-3279, 1990.

16. Tanaka RD, Lee LY, Schafer BL, et al: Molecular cloning of mevalonate kinase and regulation of its $m R N A$ levels in rat liver. Proc Natl Acad Sci USA 87: 2872-2876, 1990.

17. Flint AP: The activity and kinetic properties of mevalonate kinase in superovulated rat ovary. Biochem J 120: 145-150, 1970.

18. Flowers B, Ziecik AJ and Caruolo EV: Effects of human chorionic gonadotrophin on contractile activity of steroid-primed pig myometrium in vitro. J Reprod Fertil 92: 425-432, 1991.

19. Yoshino M, Mizutani T, Yamada K, et al: Co-activator p120 is increased by gonadotropins in the rat ovary and enhances progesterone receptor activity. Reprod Biol Endocrinol 4: 50, 2006.

20. Angioni S, Spedicato M, Rizzo A, et al: In vitro activity of human chorionic gonadotropin (hCG) on myometrium contractility. Gynecol Endocrinol 27: 180-184, 2011. 